\title{
PERBANDINGAN ESTIMASI S (SCALE) DAN ESTIMASI MM (METHOD OF MOMENT) PADA MODEL REGRESI ROBUST DENGAN DATA PENCILAN
}

\author{
Arif Semar*, Fitria Virgantari, Hagni Wijayanti. \\ Program Studi Matematika, Universitas Pakuan \\ *Corresponding Author Email: ariefsemar11@gmail.com
}

\begin{abstract}
Regression model is a model used to describe the relationship between dependent and independent variables. One method that is often used to estimate the parameters of a regression model is the OLS (Ordinary Least Square) method. In the regression model it is possible that there are outliers that cause some of the regression assumptions are violated so that the predicted value becomes inaccurate. There is method that can handle outlier can be used. One of them is the robust regression method using estimations $S$ (Scale) and MM (Method of Moment). Those methods has a high breakpointthat is maximum amount of outliers data that can be tolerated by a model. This study aims to apply and compare OLS estimates, $S$ estimates and MM estimates that contain outliers data. The data used are secondary data in the form of the ability to read a group of children aged 4 to 7 years, age, memory scores and IQ. The results showed the $S$ estimation robust regression method is the best method compared to OLS estimation and MM estimation because it has the highest $R^{2}$ value of $94.29 \%$. Based on the S estimation method obtained by the model $Y=-1,107+$ $0,484 X \_1+0.052 X \_2+0.045 X \_3$ where $Y$ is the reading score of children aged 4 to 7 years, $X_{1}$ is age, $X_{2}$ is the memory score and $X_{3}$ is $I Q$.
\end{abstract}

Keywords: outlier, MM estimation, S estimation, robust regression

\begin{abstract}
ABSTRAK
Model regresi merupakan model yang digunakan untuk menggambarkan hubungan antara variabel bebas dan tidak bebas. Salah satu metode yang sering digunakan untuk menduga parameter model regresi adalah metode OLS (Ordinary Least Square). Dalam model regresi dimungkinkan terdapat outlier (pencilan) yang menyebabkan beberapa asumsi regresi tidak terpenuhi sehingga nilai prediksi menjadi kurang akurat oleh karena itu digunakan metode yang dapat menangani data outlier. Salah satunya adalah metode regresi robust dengan menggunakan estimasi S (Scale) dan MM (Methode of Moment) karena memiliki breakpoint (jumlah maksimum data pencilan yang dapat ditoleransi oleh sebuah model) yang tinggi. Penelitian ini bertujuan untuk menerapkan dan membandingkan estimasi OLS, estimasi S dan estimasi MM yang mengandung data pencilan. Data yang digunakan adalah data sekunder berupa kemampuan membaca sekelompok anak yang berumur 4 sampai 7 tahun, umur, skor daya ingat dan IQ . Hasil penelitian menunjukkan metode regresi robust estimasi S merupakan metode terbaik dibandingkan estimasi OLS \& estimasi MM karena memiliki nilai $\mathrm{R}^{2}$ tertinggi yaitu sebesar $94,29 \%$. Berdasarkan metode estimasi $\mathrm{S}$ diperoleh model $Y=-1,107+0,484 X_{1}+0,052 X_{2}+0,045 X_{3}$ dengan $\mathrm{Y}$ adalah skor membaca anak-anak yang berumur 4 sampai 7 tahun, $X_{1}$ adalah umur, $X_{2}$ adalah skor daya ingat dan $\mathrm{X}_{3}$ adalah IQ.
\end{abstract}

Kata Kunci : pencilan, estimasi MM, estimasi S, regresi robust 


\section{PENDAhUluaN}

Analisis regresi merupakan suatu analisis yang dapat menggambarkan hubungan antara variabel bebas dengan variabel tidak bebas. Dari hubungan tersebut dapat dibuat model yang dapat memprediksi apa yang akan terjadi di masa mendatang. Salah satu metode yang sangat sering digunakan adalah metode OLS (Ordinary Least Square). Dalam model regresi dimungkinkan terdapat outlier (pencilan) yang menyebabkan beberapa asumsi regresi tidak terpenuhi sehingga nilai prediksi menjadi kurang akurat oleh karena itu digunakan metode yang dapat menangani data outlier, salah satunya adalah metode regresi robust.Adapun beberapa penelitian-penelitian tentang regresi robust yang pernah dilakukan antara lain Sahari (2012) "Model Produksi Jagung di Indonesia Menggunakan Regresi Robust Estimasi S”. Ada juga penelitian tentang "Kekekaran Regresi Linier Ganda dengan Estimasi MM (Method Of Moment) dalam Mengatasi Pencilan” yang dilakukan oleh Kurniawati (2011) . Berbeda dengan penelitian sebelumnya, pada penelitian ini akan dibandingkan antara estimasi S (Scale) dan estimasi MM (Method Of Moment) karena memiliki breakdown point (jumlah maksimum data outlier yang dapat ditoleransi oleh suatu model) yang tinggi.

\section{METODOLOGI}

\subsection{Data}

Data yang digunakan merupakan data kemampuan membaca sekelompok anak yang berumur 4 sampai 7 tahun diperoleh dari website Statistics for Psychology diambil dari http://staff.bath.ac.uk/pssiw/stats2/page16/page16.html yang berjumlah 20 data dengan 4 variabel yaitu variabel kemampuan membaca ( $Y)$, umur $\left(X_{1}\right)$, skor daya ingat $\left(X_{2}\right)$, dan IQ $\left(X_{3}\right)$.

\subsection{Tahapan Analisis}

Tahapan analisis pada penelitian ini sebagai berikut :

1. Mengumpulkan data. Data yang digunakan pada penelitian ini merupakan data umur, skor daya ingat, IQ dan kemampuan membaca sekelompok anak.

2. Memformulasikan model . Bentuk model secara umum

$$
Y_{i}=\beta_{0}+\beta_{1} X_{i 1}+\beta_{2} X_{i 2}+\cdots+\beta_{k} X_{i k}+\varepsilon_{i}
$$

Untuk model dugaan sebagai berikut : 


$$
Y_{i}=\beta_{0}+\beta_{1} X_{1}+\beta_{2} X_{2}+\beta_{3} X_{3}+\varepsilon
$$

Keterangan :

$$
\begin{array}{lll}
\mathrm{Y} & : & \text { Kemampuan Membaca } \\
X_{1} & : & \text { Umur } \\
X_{2} & : \text { Skor Daya Ingat } \\
X_{3} & : \text { IQ } \\
\beta_{0}, \beta_{1}, \ldots, \beta_{k}: & \text { Parameter regresi } \\
\varepsilon & : & \text { Nilai error }
\end{array}
$$

3. Menduga parameter dengan metode OLS dengan rumus :

$$
\hat{\beta}=\left(X^{\prime} X\right)^{-1} X^{\prime} Y
$$

dengan

$$
Y=\left[\begin{array}{c}
Y_{1} \\
Y_{2} \\
Y_{3} \\
\vdots \\
Y_{n}
\end{array}\right], \widehat{\beta}=\left[\begin{array}{c}
\hat{\beta}_{0} \\
\hat{\beta}_{1} \\
\hat{\beta}_{2} \\
\vdots \\
\hat{\beta}_{k}
\end{array}\right] \quad X=\left[\begin{array}{ccccc}
1 & X_{11} & X_{12} & \cdots & X_{1 k} \\
1 & X_{21} & X_{22} & \cdots & X_{2 k} \\
1 & X_{31} & X_{32} & \cdots & X_{3 k} \\
\vdots & \vdots & \vdots & \ddots & \vdots \\
1 & X_{n 1} & X_{n 2} & \cdots & X_{n k}
\end{array}\right], ' X=\left[\begin{array}{cccc}
n & \sum_{i=1}^{n} x_{i 1} & \cdots & \sum_{i=1}^{n} x_{i k} \\
\sum_{i=1}^{n} x_{i 1} & \sum_{i=1}^{n} x_{i 1}{ }^{2} & \cdots & \sum_{i=1}^{n} x_{i 1} x_{i k} \\
\vdots & \vdots & & \vdots \\
\sum_{i=1}^{n} x_{i k} & \sum_{i=1}^{n} x_{i 1} x_{i k} & \cdots & \sum_{i=1}^{n} x_{i k}{ }^{2}
\end{array}\right]
$$

4. Pengujian asumsi

Menurut Riadi (2014), untuk mendapatkan nilai pemeriksa yang efisien dan tidak bias dari persamaan regresi berganda dengan Metode OLS maka perlu dilakukan pengujian untuk mengetahui model regersi yang dihasilkan memenuhi persyaratan beberapa asumsi klasik yaitu :

\section{a. Uji Normalitas}

Salah satu cara untuk menguji asumsi kenormalan adalah dengan Uji KolmogorovSmirnov dengan rumus :

$H_{0}:$ Residual data berdistribusi normal

$H_{1}$ : Residual data tidak berdistribusi normal

Statistik Uji

$$
D=\max \left|F_{0}\left(X_{i}\right)-S_{n}\left(X_{i}\right)\right|, i=1,2, \ldots, n
$$

Keterangan :

$F_{0}\left(X_{i}\right)$ : Fungsi distribusi frekuensi kumulatif relatif dari distribusi teoritis dibawah sisaan distribusi normal. 
$S_{n}\left(X_{i}\right)$ : Distribusi frekuensi kumulatif pengamatan sebanyak sampel.

Apabila nilai $D>$ Dtabel, maka asumsi kenormalan tidak dipenuhi.

\section{b. Uji Heteroskedastisitas}

Uji yang digunakan untuk menguji asumsi identik adalah Uji Glejser. Hipotesis untuk Uji Glejser adalah sebagai berikut:

$H_{0}$ : Tidak ada gejala heteroskedastisitas

$H_{1}$ : Ada gejala heteroskedastisitas

Dengan statistik uji :

$$
F_{\text {hitung }}=\frac{K T R}{K T G}
$$

Pengambilan keputusan adalah Fhitung $>\mathrm{F}(\alpha, \mathrm{k}, \mathrm{n}-\mathrm{k}-1)$ maka tolak $H_{0}$ pada tingkat signifikansi $\alpha$, artinya bahwa residual tidak identik.

c. Multikolinieritas.

Salah satu cara pengujian multikolinieritas yang umum digunakan adalah pengujian VIF (Variance Inflation Factor) dengan rumus sebagai berikut :

$$
V I F=\frac{1}{\left(1-R^{2}\right)}
$$

Keterangan :

VIF : Variance Inflation Factor

$R \quad$ : Nilai korelasi antar variabel dependent

5. Mendeteksi outlier. Tahap ini mendeteksi adanya pencilan digunakan sisaan terbakukan, dengan rumus :

$$
t_{i}=\frac{e_{i}}{s_{-i} \sqrt{1-h_{i i}}}
$$

Keterangan :

$$
\begin{array}{lll}
t_{i} & : & \text { Sisaan terbakukan data ke- } i \\
e_{i} & : & \text { Nilai residual data ke- } i \\
s_{-i} & : & \text { Simpangan baku yang dihitung tanpa mengikut sertakan pengamat ke- } i \\
h_{i i} & : & \text { nilai leverage }
\end{array}
$$


dengan

$$
h_{i i}=X_{i}\left(X^{T} X\right)^{-1} X_{i}^{T}, \quad i=1,2, \cdots, n, \quad s_{-i}=\sqrt{\frac{(n-p) s^{2}-\frac{e_{i}^{2}}{\left(1-h_{i i}\right)}}{n-p-1}} s^{2}=\sum_{i=1}^{n} \frac{e_{i}^{2}}{n-p}
$$

Data dikatakan memiliki pencilan jika sisaan terbakukan $\left(t_{i}\right)>T_{(\alpha / 2, n-p-1)}$ dan dilakukan pendeteksian data pencilan yang mempengaruhi model berdasarkan nilai DfFITS. DfFITS dapat dihitung dengan rumus :

$$
\mid \text { DfFITS } \mid=\left(\frac{h_{i i}}{1-h_{i i}}\right)^{\frac{1}{2}} e_{i}\left[\frac{n-p-1}{J K G\left(1-h_{i i}\right)-e_{i}^{2}}\right]^{\frac{1}{2}}
$$

Keterangan :

$J K G \quad$ : Jumlah kuadrat galat

$k \quad: \quad$ Jumlah variabel bebas

$n \quad:$ Banyaknya pengamatan

$X_{i} \quad: \quad$ Data variabel X ke-i

Pengamatan ke- $i$ berpengaruh pada model regresi jika

$$
\mid \text { DFFITS } \mid= \begin{cases}>1 & n<30 \\ >2 \sqrt{\frac{p+1}{n},} & n \geq 30\end{cases}
$$

6. Pendugaan parameter menggunakan estimasi S dan estimasi MM jika dideteksi adanya pencilan dengan perhitungan sebagai berikut :

Menurut Pratitis dan Listyati (2016) berikut langkah-langkah menduga parameter dengan metode estimasi S :

a. Menaksir $\beta$ awal yaitu $\hat{\beta}_{(0)}$ dengan menggunakan OLS

b. Menghitung nilai residual $e_{i}=y_{i}-\hat{y}_{i}$

c. Menghitung standar deviasi sisaan $\widehat{\sigma}_{s}$ :

$$
\widehat{\sigma}_{\mathrm{s}}=\sqrt{\frac{\mathrm{n} \sum_{\mathrm{i}=1}^{\mathrm{n}}\left(\mathrm{e}_{\mathrm{i}}^{2}\right)-\left(\sum_{\mathrm{i}=1}^{\mathrm{n}} \mathrm{e}_{\mathrm{i}}\right)^{2}}{\mathrm{n}(\mathrm{n}-1)}}
$$

d. Menghitung nilai $u_{i}=\frac{e_{i}}{\widehat{\sigma}_{i}}$

e. Menghitung nilai pembobot $w_{i}$ 


$$
w_{i}=\left\{\begin{array}{rr}
{\left[1-\left(\frac{\mathrm{u}_{\mathrm{i}}}{\mathrm{c}}\right)^{2}\right]^{2},} & \left|\mathrm{u}_{\mathrm{i}}\right|<1,547 \\
0, & \left|\mathrm{u}_{\mathrm{i}}\right| \geq 1,547
\end{array}\right.
$$

f. Menghitung OLS terbobot untuk mendapatkan penduga kuadrat terkecil terbobot

$$
\hat{\beta}_{s}=\left(X^{\prime} W X\right)^{-1} X^{\prime} W Y
$$

g. Mengulangi langkah b-f sampai diperoleh nilai $\hat{\beta}_{s}$ yang konvergen.

Menurut Romdi dkk (2015) berikut langkah-langkah menduga parameter dengan metode estimasi MM:

a. Menaksir $\beta$ awal yaitu $\hat{\beta}_{(0)}$ dengan menggunakan estimasi S

b. Menghitung nilai residual $e_{i}=y_{i}-\hat{y}_{i}$

c. Menghitung standar deviasi sisaan $\widehat{\sigma}_{s}$

$$
\widehat{\sigma}_{\mathrm{s}}=\sqrt{\frac{\mathrm{n} \sum_{\mathrm{i}=1}^{\mathrm{n}}\left(\mathrm{e}_{\mathrm{i}}{ }^{2}\right)-\left(\sum_{\mathrm{i}=1}^{\mathrm{n}} \mathrm{e}_{\mathrm{i}}\right)^{2}}{\mathrm{n}(\mathrm{n}-1)}}
$$

d. Menghitung nilai $u_{i}=e_{i} / \hat{\sigma}_{i}$

e. Menghitung nilai pembobot $w_{i}$

$$
w_{i}=\left\{\begin{array}{rr}
{\left[1-\left(\frac{\mathrm{u}_{\mathrm{i}}}{\mathrm{c}}\right)^{2}\right]^{2},} & \left|\mathrm{u}_{\mathrm{i}}\right|<4,685 \\
0, & \left|\mathrm{u}_{\mathrm{i}}\right| \geq 4,685
\end{array}\right.
$$

f. Menghitung OLS terbobot untuk mendapatkan penduga kuadrat terkecil terbobot

$$
\hat{\beta}_{m m}=\left(X^{\prime} W X\right)^{-1} X^{\prime} W Y
$$

g. Mengulangi langkah b-f sampai diperoleh nilai $\hat{\beta}_{m m}$ yang konvergen

Jika data tidak memiliki pencilan, maka dilanjutkan dengan menginterpretasikan model.

7. Tahap selanjutnya yaitu memilih metode estimasi terbaik. Menurut Indra dkk (2013), menentukan metode estimasi terbaik dapat dilihat dari nilai koefisien determinasi yang paling besar, dengan rumus :

$$
R^{2}=1-\frac{\sum\left(Y_{i}-\widehat{Y}_{i}\right)^{2}}{\sum\left(Y_{i}-\bar{Y}\right)^{2}}
$$

Keterangan : 
$Y_{i} \quad$ : Nilai variabel bebas ke-i

$\hat{Y}_{i} \quad: \quad$ Nilai duga variabel bebas ke-i

8. Tahap terakhir yaitu interpretasi model, pada tahap ini diperoleh metode yang paling optimal untuk menyelesaikan masalah data yang memiliki outlier dengan menginterpretasikan model yang diperoleh sesuai permasalahan rill. Setelah itu dilanjutkan dengan kesimpulan dan memberikan saran.

\section{HASIL DAN PEMBAHASAN}

\subsection{Metode Estimasi OLS}

Metode estimasi OLS merupakan metode yang meminimumkan jumlah kuadrat galat. Berdasarkan hasil estimasi yang dibantu dengan aplikasi EVIEWS didapatkan model regresi sebagai berikut :

$$
Y=-0.106+0.466 X_{1}+0.269 X_{2}+0.025 X_{3}, \quad \mathrm{R}^{2}=0,8349
$$

dengan :

Y : Kemampuan Membaca

$X_{1}$ : Umur

$X_{2}$ : Skor Daya Ingat

$X_{3}: \mathrm{IQ}$

Besarnya koefisien determinasi model sebesar 0,8349 artinya sebesar 83,49\% kemampuan membaca seorang anak dijelaskan oleh variabel umur, daya ingat dan IQ, sisanya sebesar $16,51 \%$ dijelaskan oleh faktor-faktor diluar variabel umur, daya ingat, dan IQ. Setelah mendapatkan model regresi dilanjutkan dengan uji asumsi

\section{Uji Normalitas}

Pengujian normalitas bertujuan untuk melihat apakah sisaan dalam model berdistribusi normal berdasarkan Gambar 1 berikut 


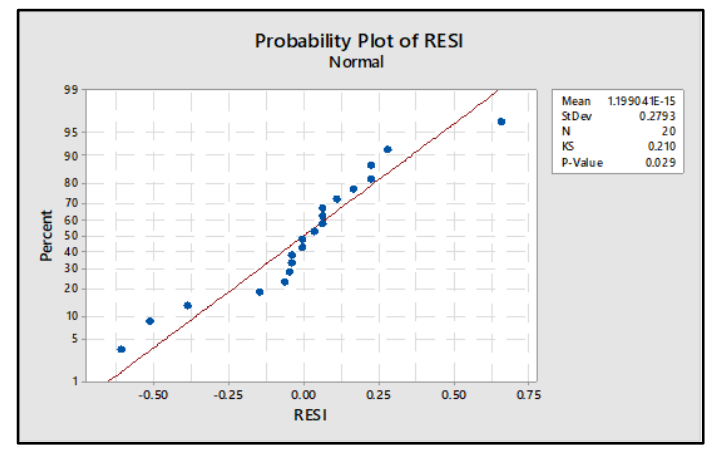

Gambar 1. Uji Normalitas

$P$-value sebesar 0,029 kurang dari taraf nyata yaitu sebesar 0,05 sehingga diambil keputusan tolah $\mathrm{H}_{0}$ maka residual tidak berdistribusi normal

\section{Uji Heteroskedastisitas}

Pengujian heteroskedastisitas bertujuan untuk mengetahui adanya kesamaan varian residual. Untuk mendeteksi heteroskedastisitas dapat dilakukan dengan uji Glesjer. Hasil uji Glesjer disajikan pada Tabel 1.

Tabel 1 Hasil Uji Heteroskedastisitas

\begin{tabular}{llll}
\hline F-statistic & 1.102690 & Prob. F(3,16) & 0.3769 \\
Obs*R-squared & 3.426619 & Prob. Chi-Square (3) & 0.3304 \\
Scaled explained SS & 3.974184 & Prob. Chi-Square (3) & 0.2643 \\
\hline
\end{tabular}

Berdasarkan Tabel 1 nilai Prob. Chi-Square (3) sebesar 0,3304 lebih besar dari tingkat kepercayaan sebesar 0,05 maka tolak $\mathrm{H}_{0}$ dapat disimpulkan varians residual bersifat homoskedastisitas.

\section{Uji Multikolinearitas}

Pengujian multikolinieritas bertujuan untuk mengetahui ada tidaknya hubungan linear antara variabel bebas. Untuk mendeteksi multikoliniearitas dapat dilakukan dengan Uji VIF (Variance Inflation Factor). Hasil Uji VIF disajikan pada Tabel 2.

Tabel 2 Uji Multikolinieritas

\begin{tabular}{cc}
\hline Variabel Bebas & VIF \\
\hline$X_{1}$ ( Umur $)$ & 3,50 \\
$X_{2}$ ( Daya Ingat ) & 3,70 \\
$X_{3}$ ( IQ ) & 1,84 \\
\hline
\end{tabular}

Berdasarkan Tabel 2 didapatkan nilai VIF $<10$ sehingga dapat dikatakan tidak terdapat masalah multikolinearitas dalam model. 


\section{Deteksi Pencilan (Outlier)}

Pencilan merupakan pengamatan yang nilai sisaannya jauh lebih besar dari sisaan lainnya. Hasil perhitungan menggunakan Software MINITAB dapat dilihat di Tabel 3.

Tabel 3 Nilai Standardized Residual \& DFFITS

\begin{tabular}{lll}
\hline No & \multicolumn{1}{c}{$t_{i}$} & \multicolumn{1}{c}{ DFFITS } \\
\hline 1 & $\mathbf{2 . 3 3 6 0 7}$ & $\mathbf{1 . 1 4 9 9 5}$ \\
2 & 0.21529 & 0.08186 \\
3 & -0.5976 & -0.4085 \\
4 & 0.36913 & 0.09547 \\
5 & 0.60267 & 0.29237 \\
6 & -0.154 & -0.0747 \\
7 & -1.4915 & $\mathbf{- 0 . 9 3 8 1}$ \\
8 & -0.1756 & -0.0826 \\
9 & $\mathbf{- 2 . 2 2 2 5}$ & $\mathbf{- 1 . 2 4 4 2}$ \\
10 & 1.04035 & 0.54517 \\
11 & $\mathbf{- 2 . 1 5 5}$ & $\mathbf{- 1 . 9 3 6 4}$ \\
12 & -0.023 & -0.0094 \\
13 & 0.12551 & 0.04703 \\
14 & -0.225 & -0.088 \\
15 & 0.8866 & 0.61183 \\
16 & -0.154 & -0.0747 \\
17 & 0.21529 & 0.08186 \\
18 & -0.023 & -0.0094 \\
19 & 0.8866 & 0.61183 \\
20 & 0.21529 & 0.08186 \\
\hline & &
\end{tabular}

Data yang termasuk pencilan jika $\left|t_{i}\right|>t_{\text {tabel }}=2.109$ dan DFFITS $>2 \sqrt{\frac{k+1}{n}}=$ 0,894, sehingga dari Tabel 3, data yang termasuk pencilan yaitu pengamatan ke-1, ke-7, ke-9 dan ke-11.

\section{Regresi Robust Estimasi S}

Karena hasil uji menyatakan ada data pencilan \& residual tidak berdistribusi normal maka dilanjutkan dengan estimasi S. Berdasarkan hasil estimasi menggunakan metode ini, didapatkan model regresi sebagai berikut :

$$
Y=-1,107+0,484 X_{1}+0,052 X_{2}+0,045 X_{3}
$$

Besarnya koefisien determinasi model sebesar 0,9429 yang artinya sebesar 94,29\% kemampuan membaca seorang anak dijelaskan oleh variabel umur, daya ingat dan IQ, 
sisanya yang sebesar 5,71\% dijelaskan oleh faktor-faktor diluar variabel umur,daya ingat, dan IQ.

\section{Regresi Robust Estimasi MM}

Berdasarkan hasil estimasi menggunakan metode ini, didapatkan model regresi sebagai berikut :

$$
Y=-1,514+0,514 X_{1}-0,008 X_{2}+0,005 X_{3}
$$

Besarnya koefisien determinasi model sebesar 0,6671 yang artinya sebesar $66,71 \%$ kemampuan membaca seorang anak dijelaskan oleh variabel umur, daya ingat dan IQ, sisanya yang sebesar 33,29\% dijelaskan oleh faktor-faktor diluar variabel umur,daya ingat, dan IQ.

\section{Signifikansi Model}

\section{Uji F}

Pengujian simultan bertujuan untuk menguji semua variabel bebas model tersebut mempunyai pengaruh secara bersamaan terhadap variabel terikat.

\section{Tabel 4 Hasil Uji F}

\begin{tabular}{clc}
\hline No & \multicolumn{1}{c}{ Model } & F hitung \\
\hline 1 & Estimasi OLS & 26,98 \\
2 & Estimasi S & 88,23 \\
3 & Estimasi MM & 10,68 \\
\hline
\end{tabular}

Berdasarkan Tabel $4\left|F_{\text {hitung }}\right|>F_{\text {tabel }}=3,238$ sehingga dapat disimpulkan bahwa setiap variabel bebas berpengaruh signifikan terhadap model.

\section{Uji T}

Pengujian parsial berfungsi untuk mengetahui adanya pengaruh variabel bebas terhadap variabel tidak bebas. Hasil perhitungan nilai $t_{\text {hitung }}$ setiap variabel model disajikan pada Tabel 5.

Tabel 5 Hasil Uji T

\begin{tabular}{cccc}
\hline Parameter & Estimasi OLS & $\begin{array}{c}\text { Nilai Hitung } \\
\text { Estimasi S }\end{array}$ & Estimasi MM \\
\hline Intercept & $-0,079$ & $-7,634$ & $-7,928$ \\
$\mathrm{X}_{1}$ & 3,819 & 27,231 & 30,235 \\
$\mathrm{X}_{2}$ & 1,115 & 2,08 & 0,244 \\
$\mathrm{X}_{3}$ & 1,667 & 22,5 & 2,5 \\
\hline
\end{tabular}


Keputusan yang diambil pada uji parsial ini adalah jika $\left|t_{\text {hitung }}\right|>t_{\text {tabel }}=2,473$

Tabel 5 menunjukkan variabel $\mathrm{X}_{1}$ dan $\mathrm{X}_{3}$ model estimasi $\mathrm{S}$ dan estimasi $\mathrm{MM}$ mempengaruhi variabel tidak bebas, sedangkan estimasi OLS dipengaruhi oleh variabel $\mathrm{X}_{1}$.

\section{Permilihan Metode Estimasi Terbaik}

Setelah mengetahui model regresi dari masing-masing parameter, dilanjutkan dengan membandingkan nilai koefisien determinasi untuk mendapatkan model terbaik.

Tabel 6 Perbandingan Nilai Koefisien Determinasi dengan Estimasi OLS, S, dan MM

\begin{tabular}{cccc}
\hline Parameter & Estimasi OLS & Estimasi S & Estimasi MM \\
\hline Intercept & $-0,106$ & $-1,107^{* *}$ & $-1,514^{* *}$ \\
Umur $\left(\mathrm{X}_{1}\right)$ & $0,466^{* *}$ & $0,484^{* *}$ & $0,514^{* *}$ \\
Daya Ingat $\left(\mathrm{X}_{2}\right)$ & 0,269 & 0,052 & $-0,008$ \\
IQ $\left(\mathrm{X}_{3}\right)$ & 0,025 & $0,045^{* *}$ & $0,005^{* *}$ \\
$\mathrm{R}^{2}$ & 0.834961 & 0.942946 & 0.667083 \\
\hline \multicolumn{2}{c}{ : signifikan pada taraf $\alpha=5 \%$}
\end{tabular}

Metode terbaik adalah metode yang memiliki nilai $\mathrm{R}^{2}$ paling besar. Dari Tabel 6 dapat dilihat nilai $\mathrm{R}^{2}$ metode estimasi $\mathrm{S}$ bernilai 0,94 lebih besar dibandingkan nilai $\mathrm{R}^{2}$ metode estimasi OLS yang bernilai 0,83 dan estimasi MM bernilai 0,66 yang artinya estimasi S merupakan metode yang paling baik digunakan untuk mengestimasi parameter regresi untuk kasus kemampuan membaca sekelompok anak.

\section{Interpretasi Model}

Pada metode regresi robust estimasi S dihasilkan model persamaan regresi sebagai berikut :

$$
Y=-1,107+0,484 X_{1}+0,052 X_{2}+0,045 X_{3}
$$

Model ini mempunyai $\mathrm{R}^{2}$ sebesar 0,9429 artinya 94,29\% variasi variabel tidak bebas dijelaskan oleh variabel bebas dan sisanya dipengaruhi oleh faktor lain. Persamaan regresi di atas dapat diuraikan sebagai berikut :

1. Koefisien regresi variabel $\mathrm{X}_{1}$ sebesar 0,484 artinya dengan menganggap variabel bebas lainnya bernilai konstan, setiap bertambahnya umur 1 tahun maka skor kemampuan membaca seorang anak akan meningkat sebesar 0,484 
2. Koefisien regresi variabel $\mathrm{X}_{2}$ sebesar 0,052 artinya dengan menganggap variabel bebas lainnya bernilai konstan, setiap bertambahnya 1 satuan skor daya ingat maka skor kemampuan membaca seorang anak akan meningkat sebesar 0,052

3. Koefisien regresi variabel $\mathrm{X}_{3}$ sebesar 0,045 artinya dengan menganggap variabel bebas lainnya bernilai konstan, setiap bertambahnya 1 satuan IQ maka skor kemampuan membaca seorang anak akan meningkat sebesar 0,045

\section{SIMPULAN}

Berdasarkan hasil analisis dan pembahasan maka dapat disimpulkan metode regresi robust estimasi S merupakan metode yang menghasilkan model terbaik dalam kasus data kemampuan membaca sekelompok anak, karena metode estimasi $\mathrm{S}$ memiliki $\mathrm{R}^{2}$ sebesar 94,29\% yang lebih besar dibandingkan $\mathrm{R}^{2}$ metode estimasi OLS sebesar $83,49 \%$ dan metode estimasi MM sebesar 66,7\%.

Berdasarkan Metode Estimasi $\mathrm{S}$ diperoleh model terbaik skor kemampuan membaca seorang anak $(\mathrm{Y})$ yang dipengaruhi oleh faktor umur $\left(\mathrm{X}_{1}\right)$, skor daya ingat $\left(\mathrm{X}_{2}\right)$ dan IQ $\left(\mathrm{X}_{3}\right)$, dihasilkan model regresi sebagai berikut : $Y=-1,107+0,484 X_{1}+$ $0,052 X_{2}+0,045 X_{3}$.

\section{SARAN}

Dalam penulisan skripsi ini Metode Regresi Robust yang digunakan adalah Metode Estimasi $\mathrm{S}$ dan Metode Estimasi MM, untuk penelitian selanjutnya dapat dicoba menggunakan estimasi robust yang lainnya seperti Metode Estimasi M (Maximum Likelihood type), LTS (Least Trimmed Square), atau LMS (Least Median Square).

Selain itu penelitian selanjutnya dapat dilakukan dengan membandingkan metodemetode yang bisa mengatasi outlier selain regresi robust seperti menghilangkan data outlier ataupun mentransformasikan data.

\section{DAFTAR PUSTAKA}

Indra S, Vionanda D, Sriningsih R. 2013. Pendeteksian Data Pencilan dan Pengamatan Berpengaruh pada Beberapa Kasus Data Menggunakan Metode Diagnostik. Journal of Mathematics. Vol. 2, No. 1, 67-74. Universitas Negeri Padang. 
Kurniawati, LD. 2011. Kekekaran Regresi Linier Ganda dengan Estimasi MM (Method of Moment) dalam Mengatasi Pencilan. Skripsi. Yogyakarta: Universitas Negeri Yogyakarta

Pratitis WD dan Listyani E. 2016. Perbandingan Metode Estimasi-M , Estimasi-S , Dan Estimasi-MM Pada Model Regresi Robust Untuk Memprediksi Produksi Kedelai Di Indonesia. Jurnal Pendidikan Matematika dan Saint. Vol. 5, No. 5. Universitas Negeri Yogyakarta

Riadi E. 2014. Metode Statistika Parametrik \& Nonparametrik. Pustaka Mandiri. Tangerang.

Romdi, Wahyuningsih S, dan Yuniarti D. 2015. Regresi Robust Linear Sederhana dengan Menggunakan Estimasi MM (Method of Memont). Jurnal Eksponensial. Vol.6. No. 2. Universitas Mulawarman. Samarinda.

Sahari R. 2012. Model Produksi Jagung di Indonesia Menggunakan Regresi Robust Estimasi S. Skripsi. Universitas Sebelas Maret. 